\title{
Social Media Addiction is linked to psychotic like experiences in Nonclinical Tunisian youth
}

\author{
Fekih-Romdhane F, Sassi H, Cheour M \\ Ibn Omrane Psychiatry Department; Razi Hospital
}

Background:" The use of social media networks has grown exponentially in the past decade. Facebook is the most popular social media platform in Tunisia (more than seven million users by early 2018), folowed by instagram (more than one million users).

Over two-thirds (74\%) of facebook users and $80 \%$ of instagram users are aged 13-34 years. These pervasive forms of communication among adolescents and young adults are particularly concerning when considering mental health.

There has been very little research to inform our understanding of how problematic social media use may relate to mental illness.

We aimed to examine the link between social media addiction and Psychotic-Like Experiences (PLEs) in a sample of nonclinical Tunisian youth.

Method: The "Positive Subscale of Community Assessment of Psychotic Experiences" and the "Arabic Social Media Addiction Scale" were administered to a total of 501 college students of the "National Institute of Applied Science and Technology" (57.5\% female; aged 18-32).

\section{Results:}

" "Persecutory Ideation", "Magical Thinking" and "Bizarre Experiences" were reported at least sometimes by $98.8 \%, 97,4 \%$ and $95,6 \%$ of the students, respectively.

* After controlling for demographic variables (gender, age) and psychosocial factors (tobacco, alcohol and drug use), social media addiction significantly contributed to PLEs $(p<0,001)$ (see table 1).

\section{Discussion:}

* To our knowledge, this is the first study to assess the relation between social media addiction and PLEs in an Arab youth population.

* Our results build on previous literature that mainly focused on general internet use, and consistently indicated an association between social media use and PLEs.

* Social media use may be an important target for early intervention in psychosis.
Table 1. Hierarchical multiple regression model correlating PLEs to social media addiction.

\begin{tabular}{lccc}
\hline \multirow{2}{*}{ Variables } & \multicolumn{3}{c}{ PLEs (CAPE total scores) } \\
\cline { 2 - 4 } & Step 1 & Step 2 & Step 3 \\
\hline Age & 0.000 & 0.001 & -0.008 \\
\hline Tobacco use & 0.030 & 0.058 & 0.034 \\
\hline Alcohol consumption & - & 0.009 & -0.005 \\
Drug use in the past year & - & $-0.111^{*}$ & -0.089 \\
\hline SMAS total scores & - & -0.041 & -0.020 \\
\hline F & - & - & $0.343^{* * *}$ \\
R2 & 0.22 & 2.55 & $66.08^{* * *}$ \\
$\Delta$ R2 & 0.001 & 0.016 & 0.132 \\
\hline
\end{tabular}

Note. Standardized $\beta$ weights reported at each step evaluate changes in weights with the inclusion of additional predictors. ${ }^{*} \mathrm{p}<0.05 ;{ }^{*} \mathrm{p}<0.01 ;{ }^{* * *} \mathrm{p}<0.001 ;$ CAPE: Community Assessment of Psychic Experiences; PLEs: Psychotic-Like Experiences; SMAS: Social Media Addiction Scale.

\section{References:}

- Mittal VA, Dean DJ, Pelletier A. Internet addiction, reality substitution and longitudinal changes in psychotic-like experiences in young adults. Early Interv

Psychiatry. 2013;7(3):261-9.

* Naslund JA, Aschbrenner KA, Bartels SJ. How people with serious mental illness use smartphones, mobile apps, and social media. Psychiatrie Rehabil J. 2016

Dec;39(4):364-367

* Highton-Williamson E, Priebe S, Giacco D. Online social networking in people with psy chosis : A systematic review. Int J Soc

Psychiatry. 2015;61(1):92101. 